expect 1.1 year decline in work-life expectancy due to poor emotional strain at work. In addition the expected time spend in sickness absence until pension age will increase by 0.9 years, and the expected time spend in unemployment will increase by 0.3 years. Similar results are made for other profiles, with or without the right to early retirement pension scheme.

Discussion Results suggest a significant influence of occupational health on work-life expectancy and work disability among Danish employees. With the new methods utilising the detailed Danish registers one have the ability to estimate work-life expectancy even for small groups, which is often the case when subgrouping levels of occupational health.

\section{LIFESTYLE AND WORK ABILITY IN A NORWEGIAN GENERAL WORKING POPULATION}

${ }^{1,2}$ Marit Müller de Bortoli*, ${ }^{1}$ Inger M Oellingrath, ${ }^{2}$ Martin Veel Svendsen, ${ }^{2}$ Anne Kristin Møller Fell. ${ }^{1}$ Faculty of health- and social sciences, Department of Nursing and Health Sciences, University College of Southeast Norway, Porsgrunn, Norway; ${ }^{2}$ Department of Occupational and Environmental Medicine, Telemark Hospital, Skien, Norway

\subsection{6/oemed-2018-ICOHabstracts.127}

Introduction There has been increasing attention on work ability promotion and prolonging working life in Norway. The aim of this study was to investigate the association between several lifestyle-related risk factors (unhealthy diet, low physical activity, overweight/obesity and smoking) and self-rated work ability.

Methods This study is based on the Telemark study, a crosssectional population study conducted in Telemark county, Norway in 2013. Complete data on lifestyle-related factors and work ability were obtained for 10434 participants aged 1850 years, all engaged in paid work during the past 12 months. The outcome measure was the first single item question of the work ability index (WAI). We used multiple logistic regression analysis to examine the associations with the independent variables: diet, body mass index, physical activity and smoking. We adjusted for age, gender, education and main occupational group and stratified for age groups (18-30, 31-40 and 41-50).

Results Reduced work ability (score <8) was more likely among obese participants (OR 1.5, 95\% CI: 1.3 to 1.7 ), past and current smokers (OR 1.3,95\% CI: 1.1 to 1.5 and $\mathrm{OR}$ 1.4, 95\% CI: 1.2 to 1.6 respectively), inactive individuals (OR 1.4, 95\% CI: 1.3 to 1.6 ), and persons responding to have an unhealthy diet (OR 1.3, 95\% CI: 1.0 to 1.5). Among participants aged 18-30 years, inactivity and smoking were associated with deceased work ability, while among participants aged 41-50 years, all the studied lifestyle-related factors were significantly associated with decreased work ability.

Discussion Lifestyle-related risk factors were found to be associated with reduced work ability in a general working population aged 18-50. The results indicate that workers may benefit from interventions focusing on multiple life style changes. The findings further indicate an increased importance of lifestyle-related behaviours on work ability with age. The results are considered relevant to occupational intervention health programs aimed at prevention of decreased work ability.

\section{SOCIOECONOMIC STATUS, DEMOGRAPHIC AND PERSONAL FACTORS, AND THE EATING BEHAVIOURS OF CIVIL SERVICE EMPLOYEES: A CROSS-SECTIONAL STUDY}

${ }^{1}$ Judith Grant*, ${ }^{1}$ Jonathan Houdmont, ${ }^{2}$ Fehmidah Munir, ${ }^{3}$ Robert Kerr, ${ }^{4}$ Ken Adley. ${ }^{1}$ University of Nottingham, Nottingham, UK; ${ }^{2}$ Loughborough University, Loughborough, UK; ${ }^{3}$ University of UIster, Newtonabbey, UK; ${ }^{4}$ Northern Ireland Civil Service, Belfast, UK

\subsection{6/oemed-2018-ICOHabstracts. 128}

Introduction This study concerns the relationship between socioeconomic status (SES) and eating behaviours in working populations. Much research exists on this topic in a community setting, however more research is needed in a workplace setting to help inform the targeting of interventions to improve employee health.

Methods The study was conducted in 2014 using a single selfreport anonymous questionnaire. The variables of interest in this study were age, gender and number of dependents, three measures of SES (education, income and job type), Body Mass Index (BMI), and diet. Two items, 'how often do you eat past the point of feeling full?' and 'to what extent does the cost of food influence what you buy?' were introduced into the survey in response to a literature review. Hierarchical linear regression analyses were conducted to examine the variance in eating behaviours.

Result A 20\% response rate was achieved with 6206 responses. All three SES variables, in addition to age, number of dependents and BMI accounted for $9 \%$ of the variance in the cost of food influencing purchase behaviours; age, gender and BMI explained $7 \%$ of the variance in eating past the point of feeling full; gender, BMI and all SES variables explained 1\% of the adjusted variance in vegetable consumption; age, gender and BMI explained $2 \%$ of the variance in fruit consumption and age, gender, BMI, education and salary band explained $5 \%$ of the variance in consumption of a healthy well-balanced diet.

Discussion The findings demonstrate the importance of socioeconomic status in eating behaviours and suggest that demographics also play a significant role in influencing employee eating behaviours. This raises interesting questions as to the feasibility of targeting healthy eating interventions at work on the basis age or BMI.

\section{A SNAPSHOT OF 3887 BELGIAN EMPLOYEE'S WORK- ABILITY: A COMPARISON BETWEEN AGE GROUPS}

\footnotetext{
${ }^{1,2}$ Sofie Vandenbroeck* ${ }^{*}{ }^{1}$ Liesbeth Aerts, 1,3 Liesbeth Daenen, Lieve Vandersmissen,

1,2Lode Godderis. 'Knowledge, Information and Research Centre, IDEWE Group (External Service for Prevention and Protection at Work), Leuven, Belgium; '2Environment and Health, Faculty of Medicine, KU Leuven, Leuven, Belgium; ${ }^{3}$ Department of Rehabilitation Sciences and Physiotherapy, Human Physiology and Anatomy (KIMA), Faculty of Physical Education and Physiotherapy, Vrije Universiteit Brussel, Brussels, Belgium
}

\subsection{6/oemed-2018-ICOHabstracts. 129}

Introduction Working life will increase due to a raise of the legal retirement age. Yet, its success will depend on the willingness and ability of workers to remain at work. Work-ability, the backbone of sustainable employability, should therefore continuously be monitored and promoted. Work-ability is determined by health and functional capacities; competences; values, attitudes and 